\title{
Viscous fingering and its effect on areal sweep efficiency during waterflooding: an experimental study
}

\author{
Zahra Kargozarfard $^{1} \cdot$ Masoud Riazi ${ }^{1,2} \cdot$ Shahab Ayatollahi $^{3}$
}

Received: 24 March 2018/Published online: 10 October 2018

(C) The Author(s) 2018

\begin{abstract}
Viscous fingering is one of the main challenges that could reduce areal sweep efficiency during waterflooding in oil reservoirs. A series of waterflooding experiments were carried out in a Hele-Shaw cell at ambient temperature during which areal sweep efficiency was estimated and techniques to ease the fingering problem were examined. The onset and propagation of viscous fingers were monitored as a function of both injection rate and injection/production positions. Image processing techniques were utilized to quantitatively investigate the propagation of fingers. The experimental results show that, under specific conditions, increasing the number of finger branches could improve the areal sweep efficiency, whereas growth of a single narrow finger has a negative impact on oil displacement efficiency. According to the obtained results, increasing the injection rate improves the areal sweep efficiency up to a critical rate at which viscous fingers start to grow. The impact of heterogeneity of the medium on distributing the viscous fingers was also investigated by introducing two different arrangements of fractures in the model. The results show that fractures perpendicular to the direction of flow would distribute the displacing water more uniformly, while fractures in the direction of flow would amplify the unfavorable sweep efficiency.
\end{abstract}

Keywords Viscous fingering · Areal sweep efficiency · Front instability · Mobility ratio · Fractures · Hele-Shaw cell

\section{Introduction}

During waterflooding, water is injected into a well or pattern of wells to drive oil into production wells. The mechanism of displacing a fluid by another fluid is relatively simple; if the displaced fluid has a tendency to move more easily than the displacing one, injected fluid (water) does not overtake the displaced fluid (oil) and the interface between two fluids remains stable. When the displacing fluid moves more easily than the displaced one, tongues of

Edited by Yan-Hua Sun

Masoud Riazi

mriazi@shirazu.ac.ir

1 Enhanced Oil Recovery (EOR) Research Centre, IOR-EOR Research Institute, Shiraz University, Shiraz, Iran

2 Department of Petroleum Engineering, School of Chemical and Petroleum Engineering, Shiraz University, Shiraz, Iran

3 Enhanced Oil Recovery (EOR) Research Center, School of Chemical and Petroleum Engineering, Sharif University of Technology, Tehran, Iran displacing fluid form at the interface. This phenomenon is known as viscous fingering. In two-phase fluid flow in a porous medium, there are two main forces, viscous and capillary, that compete in the medium. The type of displacement is strongly dependent on the relative magnitude of these two forces which is defined by the capillary number. The capillary number is a dimensionless number that is defined as the ratio of viscous to capillary forces. Viscous fingering occurs at a high capillary number, when viscous forces dominate over the capillary forces (Weitz et al. 1987; Lake 1989; Løvoll et al. 2005). This happens when a fluid with lower viscosity is injected to displace a more viscous fluid (Saffman 1986). The higher the injection rate the more unstable the interface between the fluids will be, and the finger patterns will be more complicated (Duan and Wojtanowicz 2007; Løvoll et al. 2005).

Saffman and Taylor and Blackwell et al. showed that challenges of oil recovery become more severe with increasing mobility ratio. Saffman and Taylor investigated the process of formation and growth of fingers using an immiscible system in a small Hele-Shaw model. They showed that when the mobility ratio between two fluids is 
very high a single finger could control the whole displacement process (Saffman and Taylor 1958; Blackwell et al. 1959).

Sarma surveyed viscous fingering in porous media as a function of several parameters such as viscosity difference between the displaced and displacing phases, injection rate, interfacial tension and direction of saturation changes (i.e., imbibition and drainage) (Sarma 1986). He showed that viscous fingering is more pronounced in drainage; hence, imbibition is a more efficient process compared to drainage. It was found that the length of fingers can be closely related to the injection rate; also, the tip length of the fastest growing finger usually tends to flow linearly.

Turta et al. studied waterflooding in a Hele-Shaw model, and they used a vertical injection well and a horizontal production well to reduce the unfavorable gravity effect. This method improved sweep efficiency compared to conventional waterflooding techniques. The results of this work which was undertaken with different types of oil and injection rates showed that, although at breakthrough time, the oil recovery is almost the same; the ultimate oil recovery would be higher using the new technique. It is because of vertical sweep efficiency improvement of the former method (Turta et al. 2002).

Voroniak et al. used a Hele-Shaw cell to investigate the improvement in oil displacement during chemical flooding. For this purpose, the sweep efficiency of different injected fluids (i.e., water, surfactant, polymer and surfactantpolymer) at different injection rates was measured before and after breakthrough. The addition of chemicals after water breakthrough leads to fingers propagating in the unswept water zones; consequently, sweep efficiency was improved. Their results also confirm that the injection of polymer with surfactant has a synergistic effect and leads to higher recovery than surfactant or polymer injection separately (Voroniak et al. 2016).

Oil recovery is a strong function of sweep efficiency, especially when water displaces viscous oil in a reservoir. The formation and growth of fingers control the sweep efficiency and critically affect the oil recovery efficiency (Fanchi et al. 1990). Some of the important phenomena, which could decrease the displacement efficiency during waterflooding process, include:

- Water channeling due to reservoir heterogeneity,

- Gravity segregation due to density difference between oil and water,

- Unfavorable mobility ratio between oil and water due to viscosity difference.

The first factor would adversely affect the areal sweep efficiency, while the second factor reduces the vertical sweep efficiency.
Although viscous fingering has been extensively studied both theoretically and experimentally, it is attractive to study the impact on sweep efficiency during waterflooding at the pore scale. The objective of this study is to investigate viscous fingering and its effect on areal sweep efficiency during waterflooding by visualizing and quantifying the flow process in a Hele-Shaw model. For this purpose, the onset and propagation of fingers are monitored as a function of several parameters such as injection rate, the position of injection and production wells and the heterogeneity of the model. This paper presents a different viewpoint of viscous fingering. To the best of our knowledge, the effect of heterogeneity and number of injection wells in the Hele-Shaw model was experimentally investigated for the first time. Contrary to the existing published works, some circumstances observed in this study indicate the improvement of areal sweep efficiency during viscous fingering propagation. Experimental observations of this study provide a better understanding of the microscale mechanics of the displacement during waterflooding.

\section{Experimental}

A series of waterflooding tests was performed, using a Hele-Shaw model. A Hele-Shaw cell is a device whose essential features include two closely spaced parallel glass plates containing a thin layer of viscous fluid, which is mostly used to mimic fluid flow in porous media (Kim et al. 2009; Martin et al. 2002). To eliminate the effect of gravity, the model was placed horizontally. The absence of strong capillary forces in the Hele-Shaw model makes it suitable for highlighting viscous fingering. This model enables us to have a better understanding of the types of displacement between the oil and water phases (Hamida and Babadagli 2005).

\subsection{Materials}

Distilled water was used as the water phase, and a watersoluble dye was added to the water phase in order to be able to trace the flow of fluids $(10 \mathrm{~mL}$ color $/ 100 \mathrm{~mL}$ water). The dye cannot diffuse into the oil and provides a sharp front which helps the image processing of the results. An oil sample from an oil reservoir located in the south of Iran was used as the oil phase. The properties of each phase are shown in Table 1.

Interfacial tension (IFT) between the two phases was experimentally measured to be $20 \mathrm{mN} / \mathrm{m}$. It should be noted that in all the following images, the green color represents the water phase and the colorless part shows the oil phase. 
Table 1 Properties of materials

\begin{tabular}{lll}
\hline Phase & Density, $\mathrm{g} / \mathrm{cm}^{3}$ & Viscosity, $\mathrm{cP}$ \\
\hline Water phase & 1.019 & 1.013 \\
Oleic phase & 0.845 & 6.277 \\
\hline
\end{tabular}

\subsection{Experimental setup}

The Hele-Shaw cell consists of two parallel plates of flat glass, of $10-\mathrm{cm}$ length by $15-\mathrm{cm}$ width and $0.3-\mathrm{mm}$ thickness that was sealed using special resins. The opening between the glass plates is $0.07 \mathrm{~mm}$. The input and output were installed in the model. A syringe pump was used to inject fluids at a constant flow rate. Images were captured using a digital camera; the light source helped us to have clearer images. A differential pressure gauge was also used to indicate the pressure difference over the micromodel during the injection process. The experimental setup is shown in Fig. 1.

\subsection{Experimental method}

The tests performed were divided into the three following groups:

(a) Single input/single output Hele-Shaw model. The objective of using this model was to investigate the effect of flow rate on viscous fingering.

(b) Two input/one output Hele-Shaw model. Two inputs were set in series, with a distance between them of $4 \mathrm{~cm}$. In this section, the effects of injection and production positions on the formation and distribution of fingers were examined. This step was followed by testing a model with two distributors at the entrance and exit. The distributors were inserted into the model by etching the masked glass with hydrofluoric (HF) acid.

(c) Heterogeneous Hele-Shaw model with two fractures. A combination of two fractures was introduced into the model by etching the masked glass in HF. The length of each fracture was $3 \mathrm{~cm}$, and the distance between them was $2 \mathrm{~cm}$. The purpose of using this model was to study the effect of heterogeneity on

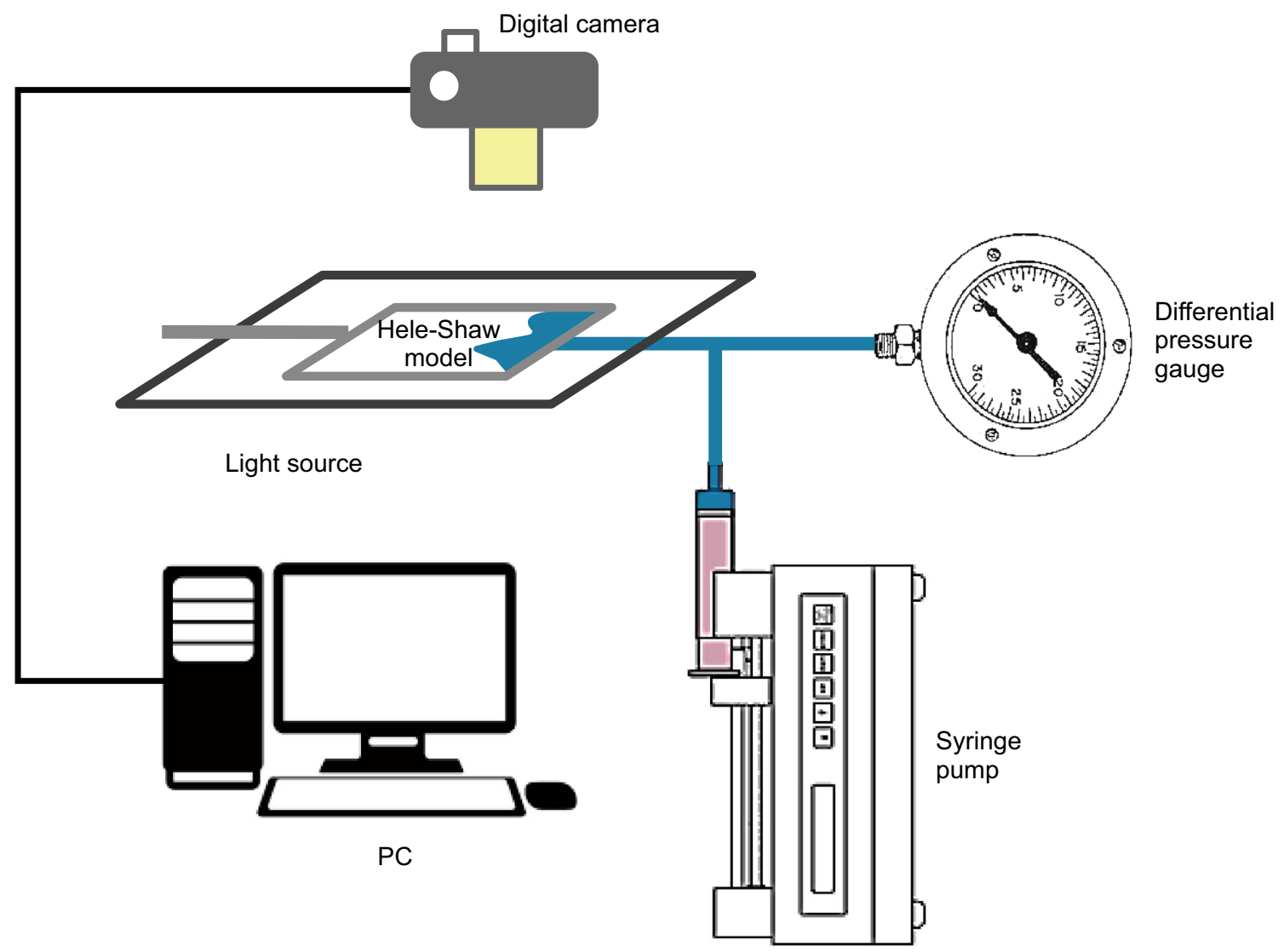

Fig. 1 Experimental setup 
viscous fingering. The effect of fracture arrangement was also investigated at this step. For this purpose, two similar tests were performed on the same model, while the direction of waterflooding was reversed in the second test.

All the experiments were carried out at ambient conditions. The following sequence was applied for each test.

1. Saturating the model with dyed distilled water. The pore volume of the model was estimated by measuring the required volume of water used to fully saturate the model.

2. Oil flooding the water-saturated model at a rate of $1 \mathrm{~mL} / \mathrm{min}$ to reach initial oil and irreducible water saturation condition.

3. Waterflooding the model until reaching the residual oil saturation condition.

4. Washing the model by injection of several pore volumes of water and acetone.

5. Steps 1-3 were repeated with different flow rates [in section (a), three flow rates of $0.2,0.5$ and $1 \mathrm{~mL} / \mathrm{min}$ were examined; in section (b), two flow rates of 0.5 and $1 \mathrm{~mL} / \mathrm{min}$ were examined; in section (c), only flow rate of $1.0 \mathrm{~mL} / \mathrm{min}$ was tested].

The flow of fluids through the model was recorded by a video camera during experiments, and then images were retrieved at desirable time periods. The pressure drop at related time was also recorded. Image processing was used to obtain the areal sweep efficiency at each condition. Areal sweep efficiency, $E_{\mathrm{A}}$, is defined by the ratio of area contacted by the displacing agent divided by the total area. In this study, a program was developed to distinguish the area of the model images occupied by the two phases. The program first performs the preprocessing of the Hele-Shaw images (e.g., gray thresholding and the selection of the region of interest). Then in short, the developed code uses a search algorithm to find different connected elements in the image. A pixel is assigned to a cluster (a known set, i.e., a certain phase), and via its connectivity matrix, the neighboring pixels which belong to that phase are found. By following this search algorithm, all pixels of the image which belong to a specific phase are found and labeled by the program. Knowing the number of pixels, the area occupied by each phase is recognized. The search algorithm is explained in depth by Haralick and Shapiro (1992).

It should be pointed that in the two inputs/one output model, water was injected simultaneously at two ports but the pressure gauge was only used in one port. At all of these experiments, the injection of fluids at three stages was carried out from the same side.

\section{Results and discussion}

Initiation and propagation of fingers depend on several parameters such as the mobility ratio between the displaced and displacing fluids, porosity, permeability, heterogeneities and local pressure drop (Collins 1976). Heterogeneity has the main effect on the flow pattern (Greenkorn and Haselow 1988). In this study, the heterogeneities were simulated by introducing two different arrangements of fractures. The balance between capillary, gravity and viscous forces affects the rate of viscous finger propagation as well (Lake 1989). The fingers grow both in length and in width (Perkins et al. 1965). It was proved that the position of injection and production as well as the direction of their growth can merge fingers or promote their growth. A possible mechanism for the formation of the periodic fingertips and their possible separation lies in the fading or pinching-off that was described by Zimmerman and Homsy (1991). Our observation showed that the rate of finger growth in length and width as well as the number of their branches could have a considerable effect on the areal sweep efficiency.

To have a better understanding of the ratio of viscous force to capillary force, the equivalent capillary number $\left(N_{\text {ca }}\right)$ defined as $\mu U_{\mathrm{F}} / \sigma$ was also calculated. In this definition, $\mu, U_{\mathrm{F}}$ and $\sigma$ are dynamic viscosity of injected fluid, velocity of the fastest advancing finger and interfacial tension, respectively (Fanchi and Christiansen 1989). In this study, each advancing front from the main front has been considered as a finger. These fingers differ from the main front in both size and direction. It should be noted that new branches might be developed from these fingers as well.

The capillary numbers in the experiments of this study are in the order of $10^{-4}$ (ranging from $1.03 \times 10^{-4}$ to $3.95 \times 10^{-4}$ ). At the field conditions, a capillary number $10^{-6}$ is considered as the critical number for capillary dominant conditions. That is, at the higher capillary numbers which we encountered in this study, the viscous forces dominate.

\subsection{Single input/single output models}

As it can be seen from Fig. 2, at the early stage of injection, the lowest areal sweep efficiency is related to the flow rate of $1.0 \mathrm{~mL} / \mathrm{min}$; this could be due to the adverse effect of fingering at the early stage of flooding on oil displacement. Areal sweep efficiency at a flow rate of $0.5 \mathrm{~mL} / \mathrm{min}$ is, however, very close to that at a flow rate of $0.2 \mathrm{~mL} / \mathrm{min}$, up to one pore volume injection. However, as injection continues, areal sweep efficiency at the rate of $0.5 \mathrm{~mL} / \mathrm{min}$ would go above that of the rate of $0.2 \mathrm{~mL} / \mathrm{min}$. This could 


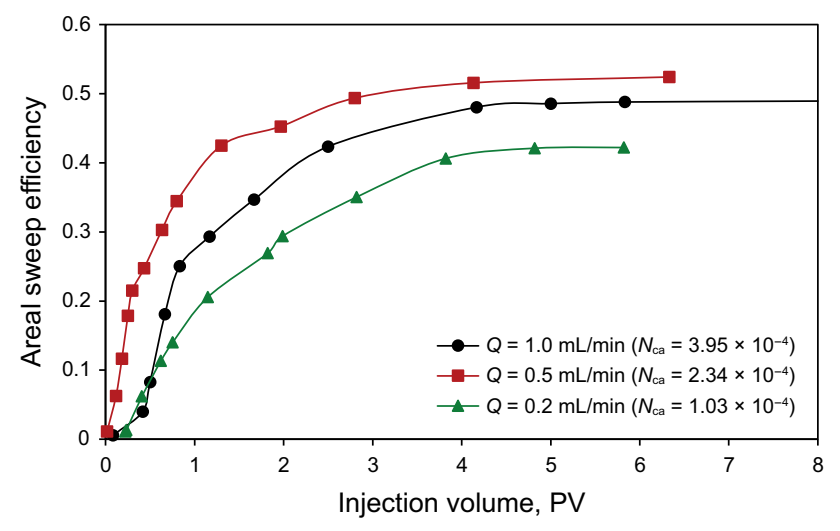

Fig. 2 Effect of injection rate on areal sweep efficiency in one input/ one output model

be due to overcoming the higher viscous force which has trapped the remaining oil after breakthrough.

According to Fig. 3, with increasing injection rate, the fingers start to grow. For an injection rate of $0.2 \mathrm{~mL} / \mathrm{min}$, no finger was observed to form prior to water breakthrough (Fig. 3a, b). After water breakthrough, branches of fingers started to form around the main front (Fig. 3c). Growth of fingers at this condition improved the areal sweep efficiency and helped to have high oil displacement efficiency even after water breakthrough. Finally, trapping takes place as a result of capillary force (Fig. 3d) (Peters and Flock 1981; Greenkorn and Haselow 1988).

The same results were observed for the injection rate of $0.5 \mathrm{~mL} / \mathrm{min}$. In this circumstance, a significant portion of trapped oil was produced because of the dominant effects of viscous forces over the capillary forces. The findings of this study indicate that a flow rate of $0.5 \mathrm{~mL} / \mathrm{min}$ is the critical flow rate at which onset of viscous fingering occurs; the fingers try to form before breakthrough, but the viscous force is not enough to provide an appropriate condition to keep the fingers. Hence, before the fingers grow, they disappear. This observation was also reported by others (Chuoke et al. 1959). As a consequence, this rate was the best condition to have an optimum injection process. Figure $4 \mathrm{a}-\mathrm{d}$ shows the onset and propagation of viscous fingers at this condition.

At a flow rate of $1.0 \mathrm{~mL} / \mathrm{min}$, fingers formed at the start of flooding. Before water breakthrough, three narrow fingers dominated the flow (Fig. 5a, b). The fastest finger grew linearly without considerable thickening, whereas two others had a small increase in width. This observation is consistent with the earlier research results (Lake 1989; Turta et al. 2002). This type of finger growth makes the process inefficient and hinders the oil production. After breakthrough, large numbers of sub-branches were generated that improved the areal sweep efficiency (Fig. 5c). A comparison between two flow rates of 0.2 and $1.0 \mathrm{~mL} / \mathrm{min}$ shows that before breakthrough, flooding with a lower injection rate is more efficient because of the stable displacing front, whereas long-term flooding shows a better result at a higher injection rate. That is, high injection rate overcomes the resistance caused by capillary forces; hence, trapped oil can be produced (Fig. 5d).

A summary of experimental results in this section is shown in Table 2. It can be seen that the breakthrough time is reduced by increasing the injection rate. At a flow rate of $1.0 \mathrm{~mL} / \mathrm{min}$, the value of areal sweep efficiency was very
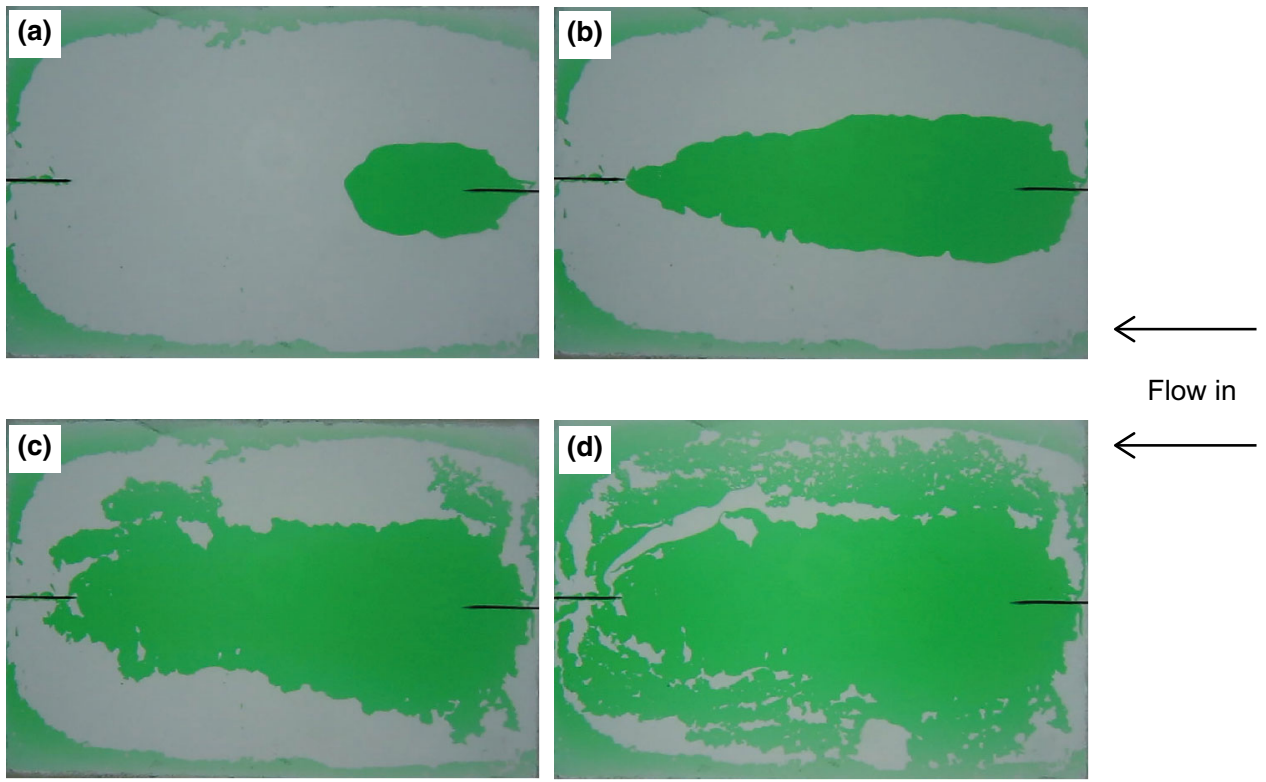

Flow in

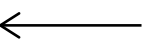

Fig. 3 Distribution of fluids during waterflooding of one input/one output model at a flow rate of $0.2 \mathrm{~mL} / \mathrm{min}$. a Before breakthrough. b At breakthrough. c After breakthrough. d Final state 

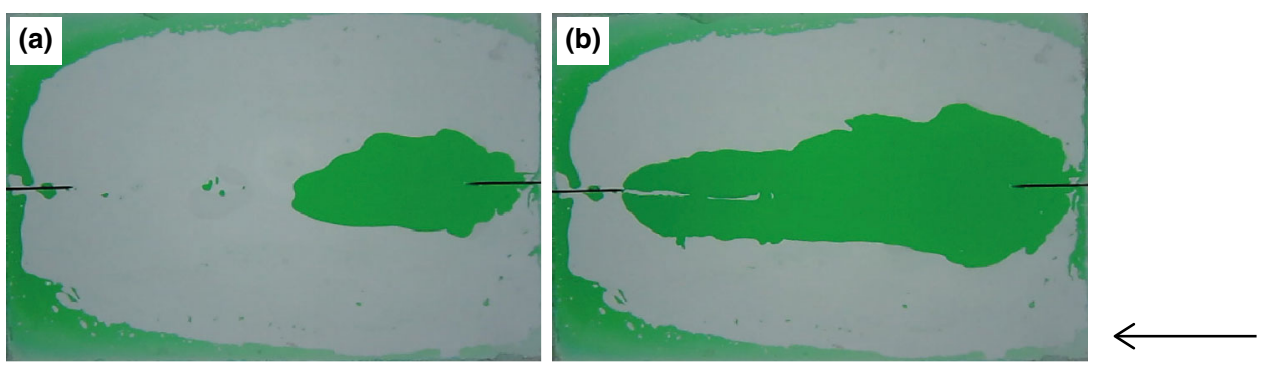

Flow in
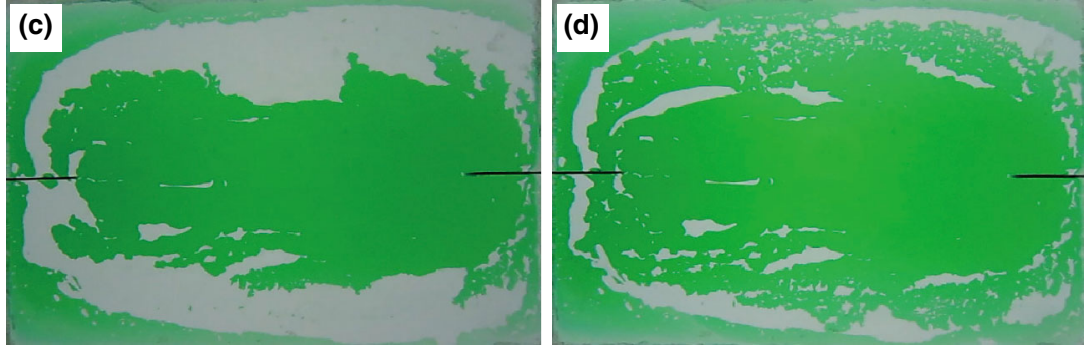

$\leftarrow$

Fig. 4 Distribution of fluids during waterflooding of one input/one output model at a flow rate of $0.5 \mathrm{~mL} / \mathrm{min}$. a Before breakthrough. b At breakthrough. c After breakthrough. d Final state
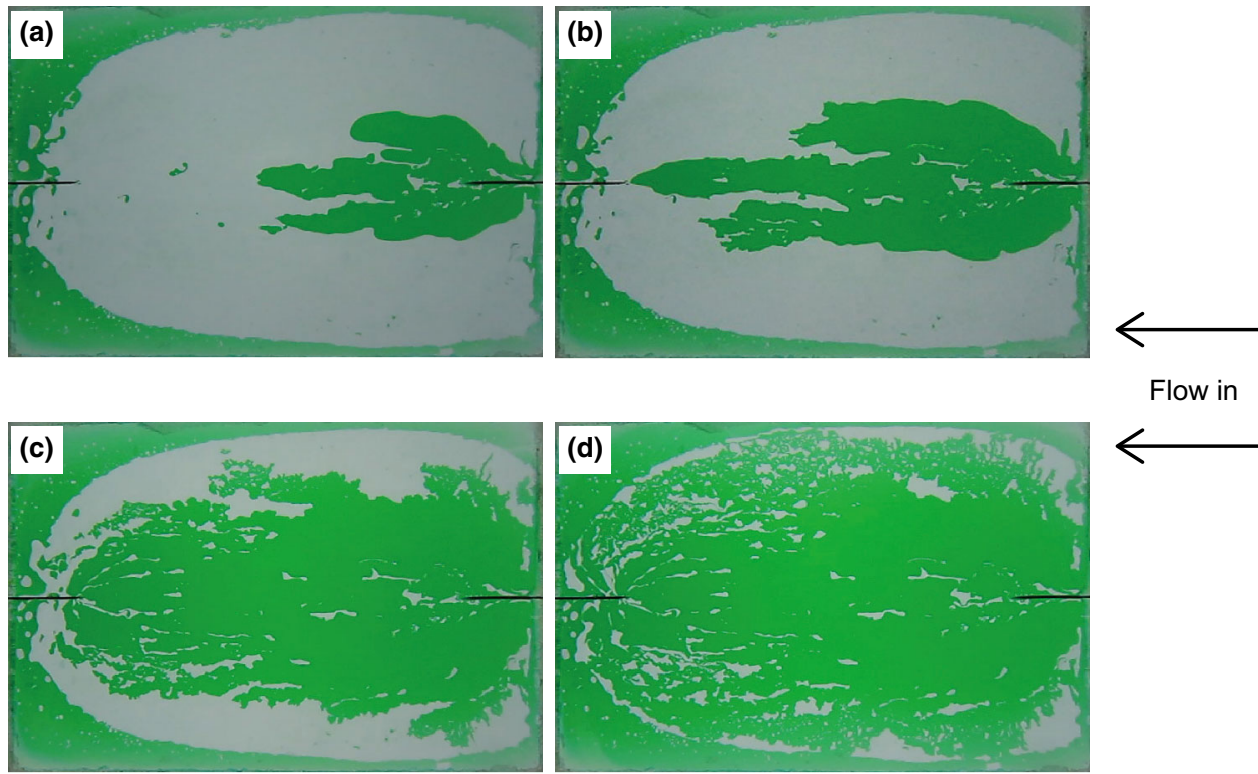

Flow in

Fig. 5 Distribution of fluids during waterflooding of the one input/one output model at a flow rate of $1.0 \mathrm{~mL} / \mathrm{min}$. a Before breakthrough. b At breakthrough. c After breakthrough. d Final state

Table 2 Experimental results in three different scenarios performed with one input/one output models

\begin{tabular}{llllll}
\hline Model & $\begin{array}{l}\text { Flow rate, } \\
\mathrm{mL} / \mathrm{min}\end{array}$ & $\begin{array}{l}\text { Breakthrough } \\
\text { time, s }\end{array}$ & $\begin{array}{l}\text { Cumulative injection volume at } \\
\text { breakthrough, PV }\end{array}$ & $\begin{array}{l}\text { Areal sweep efficiency at } \\
\text { breakthrough }\end{array}$ & $\begin{array}{l}\text { Final areal sweep } \\
\text { efficiency }\end{array}$ \\
\hline One input/one & 0.2 & 73 & 0.243 & 0.145 & 0.45 \\
output model & 0.5 & 32 & 0.266 & 0.194 & 0.53 \\
& 1.0 & 19 & 0.317 & 0.027 & 0.49 \\
\hline
\end{tabular}




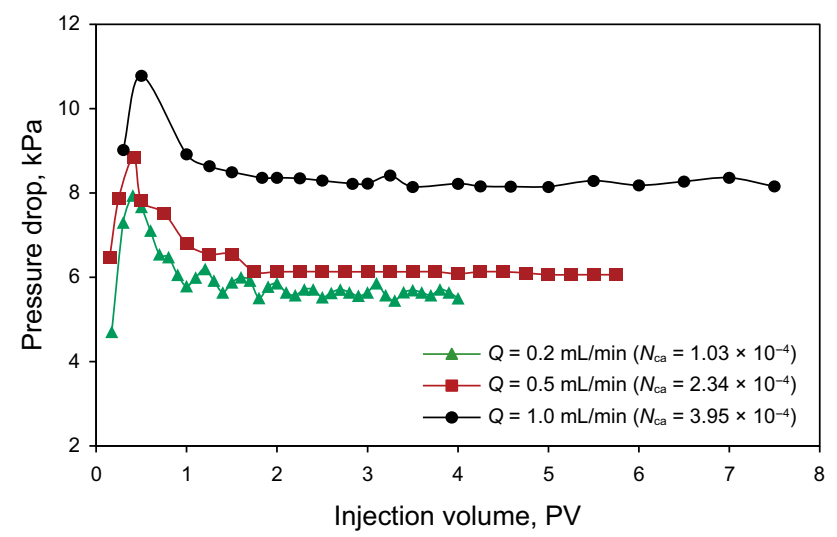

Fig. 6 Pressure drop across the model in the one input/one output case at different flow rates

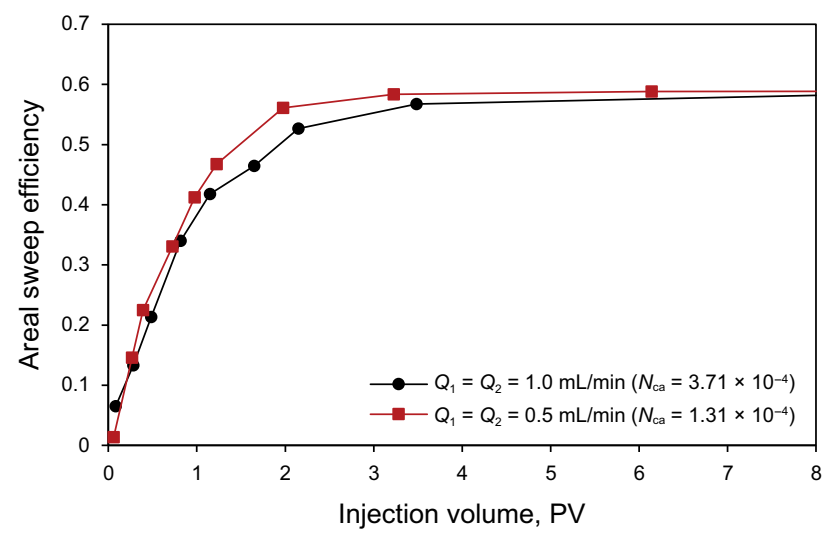

Fig. 7 Effect of flow rate on areal sweep efficiency in two input/one output models low at the breakthrough in spite of the greater amount of water injected. However, there was an optimum injection rate, which was $0.5 \mathrm{~mL} / \mathrm{min}$ in this study at which the maximum oil displacement occurs.

Figure 6 shows a simple plot of the water phase pressure drop versus the volume of fluids injected. As can be seen, the pressure drop increased up to the breakthrough point. After breakthrough, the pressure started to decrease and when the fluid distribution was fixed, the pressure drop remained unchanged.

\subsection{Two input/one output models}

With regard to our objective of investigation of viscous fingering process, further experiments were performed with the injection rate equal to or greater than the critical value. In this situation, the sweep efficiency was slightly higher at an injection rate of $0.5 \mathrm{~mL} / \mathrm{min}$. As can be seen from Fig. 7, the difference is pronounced in the range of 1-3 PV of injection; the results show that before water breakthrough there was no significant advantage of injection at lower injection rates. As mentioned already, continuing injection led to production of trapped oil at a flow rate of $1.0 \mathrm{~mL} / \mathrm{min}$ because the viscous force is dominant and the sweep efficiency almost becomes the same for both flow rates. It seems that more injection ports decrease the undesirable effect of viscous fingering. It was observed that when the injected water entered the model from the second input line, the fingers which had been already generated were diminished as a result of initiating a second oil displacement toward the fingers. As sequential images of
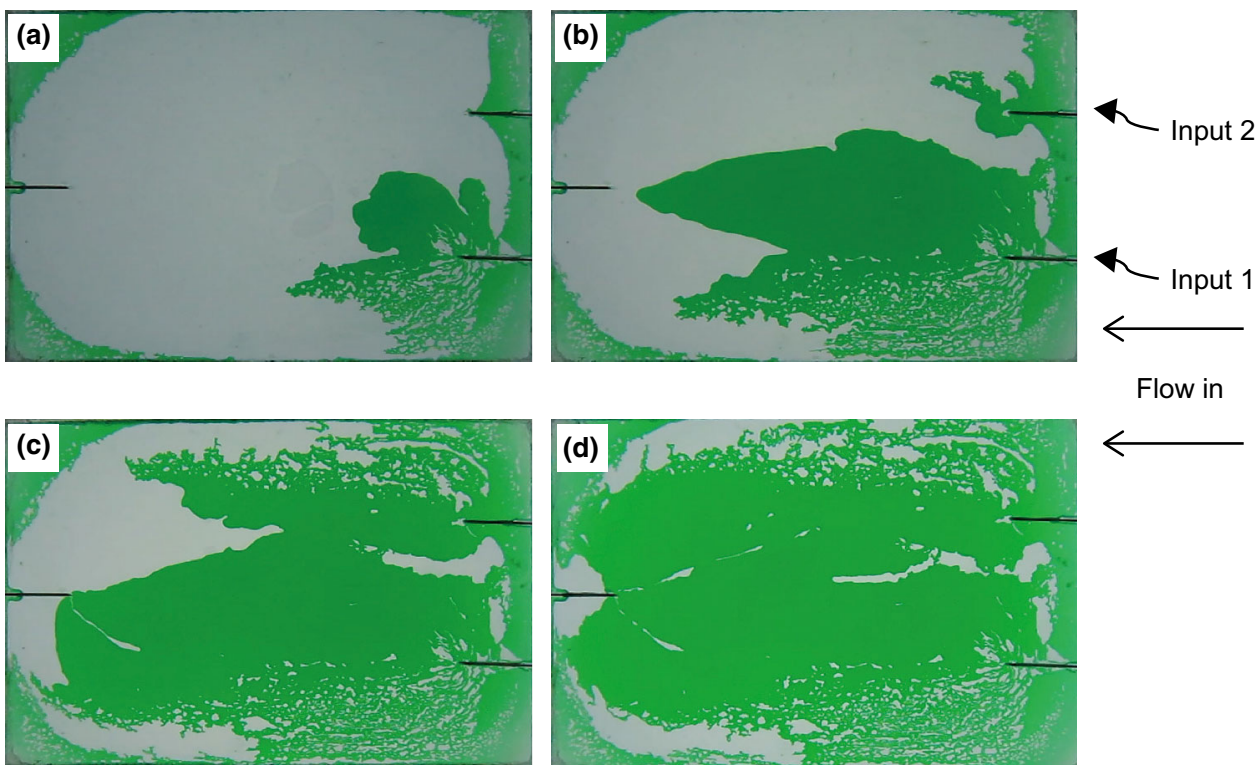

Fig. 8 Distribution of fluids during waterflooding of the two input/one output models, $Q_{1}=Q_{2}=0.5 \mathrm{~mL} / \mathrm{min}$. a Water enters from the first input. b Water enters from the second input. c Junction of two fronts. d Final state 
Fig. 8 show, the water injected from the second input prevented the generation and propagation of new fingers, especially between the two main water branches. Hence, at this condition, a stable front formed between the two injection inputs that led to better areal sweep efficiency.

In the one input/one output model, the fingers emerged symmetrically (Figs. 3a, b, 5a, b); however, when water was injected from two injection points, asymmetrical patterns were observed around each input. At this situation, branches of fingers were not observed to form in the distance between two inputs (Fig. 8a-d); the water entered from the second input pushed the oil toward the output, and this could be one of the reasons of fingers breaking. Of course, the fingers were formed on the outer sides of each input, especially at higher injection rates. However, between the two input ports, two single fingers were observed, which joined to each other. This joining phenomenon resulted in some oil trapping in this area. Comparison of Figs. 8 and 9 shows that initially the amount of trapped oil is more at the higher flow rate (i.e., $1.0 \mathrm{~mL} /$ $\mathrm{min}$ ); however, a considerable amount of this oil is produced by the end, while at the lower flow rate (i.e., $0.5 \mathrm{~mL} /$ $\mathrm{min}$ ) viscous forces are not enough to produce oil compared to the higher injection rate case.
A summary of the results of different scenarios in this section is shown in Table 3. It can be seen that the breakthrough time reduced by increasing the injection rate. However, the final displacement efficiencies were the same for both experiments.

Figure 10 compares the areal sweep efficiencies estimated for one input/one output and two input/one output models with different injection rates.

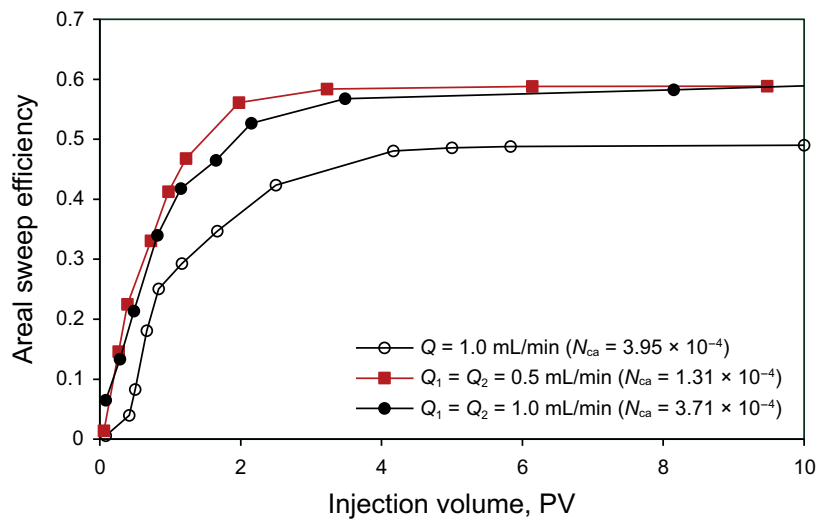

Fig. 10 Effect of number of injection ports on areal sweep efficiency
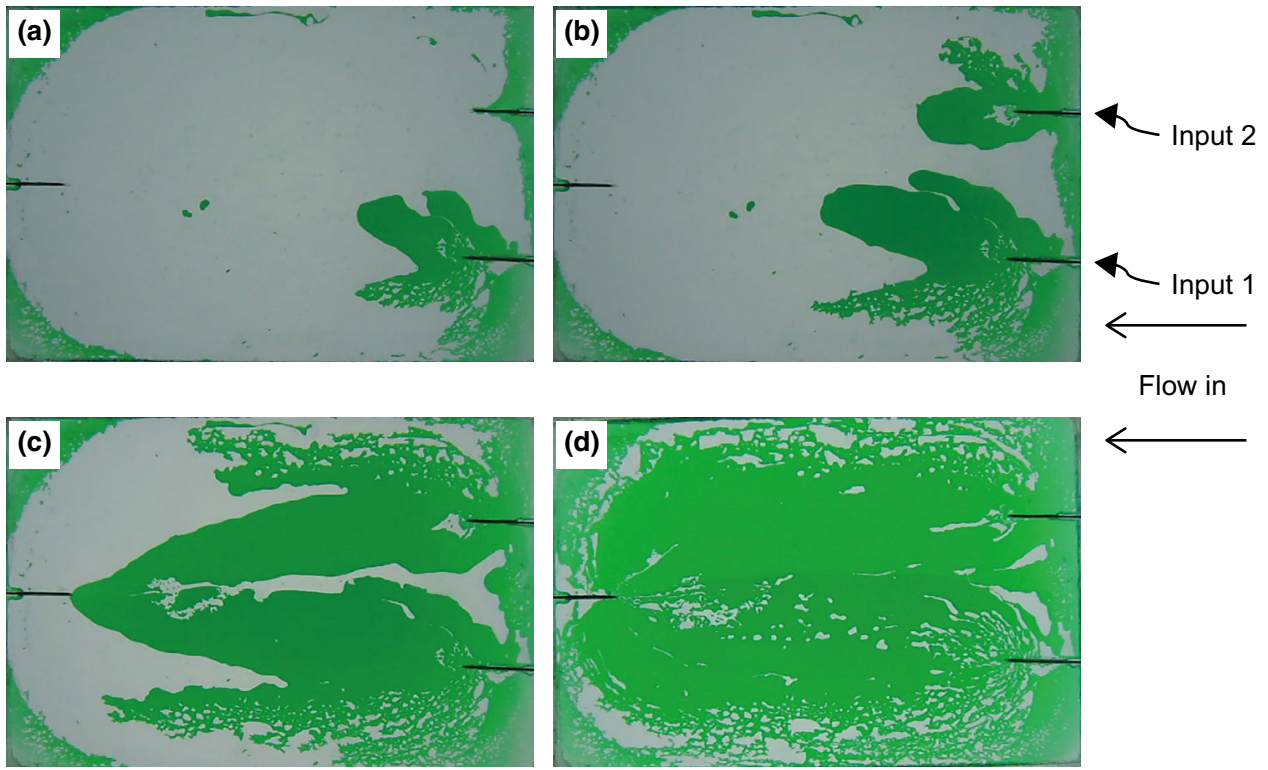

Flow in

Fig. 9 Distribution of fluids during waterflooding of two input/one output models, $Q_{1}=Q_{2}=1.0 \mathrm{~mL} / \mathrm{min}$. a Water enters from the first input. b Water enters from the second input. c Junction of two fronts. d Final state

Table 3 Experimental results in two scenarios performed with two input/one output models

\begin{tabular}{lllllll}
\hline Model & $\begin{array}{l}\text { Flow rate } Q_{1}, \\
\mathrm{~mL} / \mathrm{min}\end{array}$ & $\begin{array}{l}\text { Flow rate } Q_{2}, \\
\mathrm{~mL} / \mathrm{min}\end{array}$ & $\begin{array}{l}\text { Breakthrough } \\
\text { time, s }\end{array}$ & $\begin{array}{l}\text { Cumulative injection volume } \\
\text { at breakthrough, PV }\end{array}$ & $\begin{array}{l}\text { Areal sweep efficiency } \\
\text { at breakthrough }\end{array}$ & $\begin{array}{l}\text { Final areal } \\
\text { sweep efficiency }\end{array}$ \\
\hline $\begin{array}{c}\text { Two input/one } \\
\text { output models }\end{array}$ & 0.5 & 0.5 & 52 & 0.475 & 0.211 & 0.58 \\
\hline
\end{tabular}




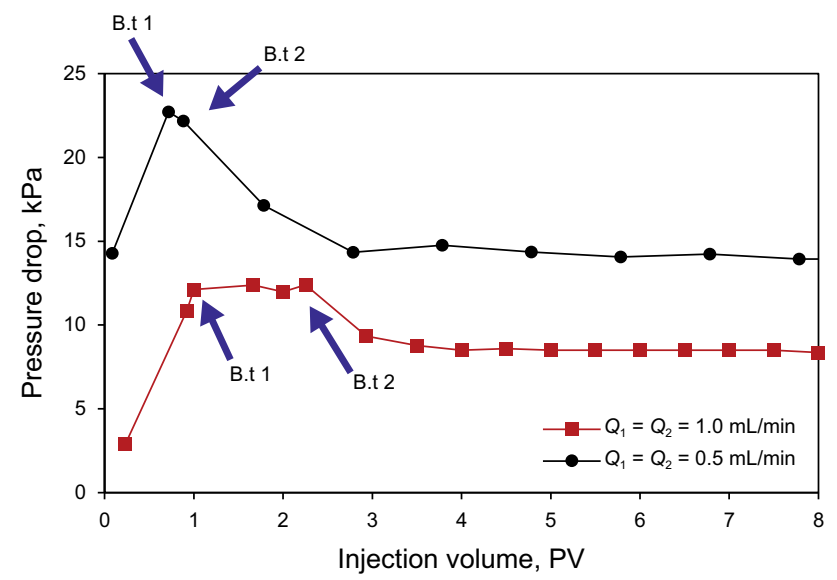

Fig. 11 Pressure drop during waterflooding across the micromodel

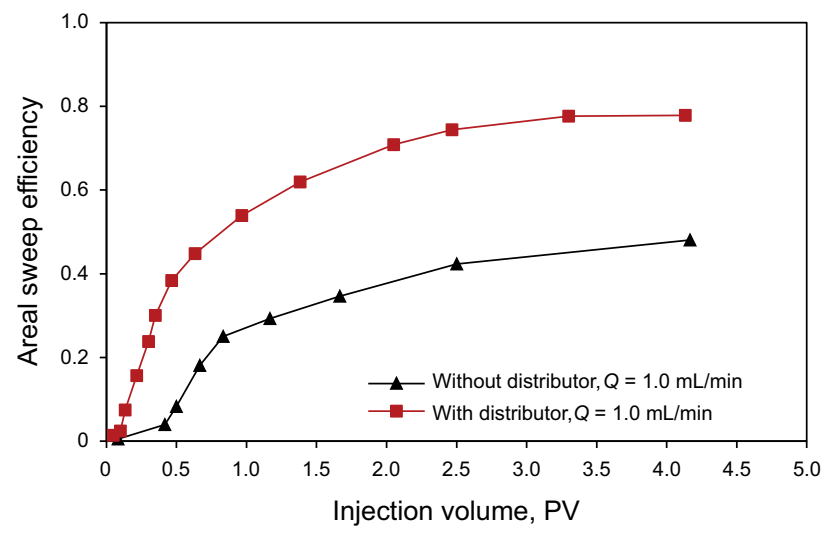

Fig. 12 Areal sweep efficiency versus water volume injected into the model with and without distributor
As the results show, an additional input could considerably improve areal sweep efficiency at the same time with a similar volume of water injected into the models at the same total injection rate (i.e., $Q=1.0 \mathrm{~mL} / \mathrm{min}$ case compared to $Q_{1}=0.5 \mathrm{~mL} / \mathrm{min}, Q_{2}=0.5 \mathrm{~mL} / \mathrm{min}$ case). This improvement in areal sweep efficiency could be due to both lower local injection flow rate in the two input/one output models (i.e., $Q_{1}=0.5 \mathrm{~mL} / \mathrm{min}, Q_{2}=0.5 \mathrm{~mL} / \mathrm{min}$ case) compared to one input/one output model (i.e., $Q=1.0 \mathrm{~mL} / \mathrm{min}$ case) that could reduce unfavorable effect of viscous fingering and the role of second water stream on diminishing the previously generated fingers within the models.

The similar results obtained from the two input/one output models with two different rates (i.e., $Q_{1,2}=0.5 \mathrm{~mL} /$ min and $Q_{1,2}=1.0 \mathrm{~mL} / \mathrm{min}$ ) indicate that the latter reason could be the dominant mechanism for improving areal sweep efficiency. As was mentioned earlier, fluid injected from the second port prevented the growth of fingers and to some cases diminished the fingers already generated in the model. This configuration formed a more stable displacement front. Based on the results of this figure, it can be concluded that there could be other parameters beside injection flow rate that would optimize the waterflooding process.

Figure 11 shows the pressure drop during waterflooding across the model. The results show that at the interval between two breakthroughs (i.e., breakthrough of waterfront from input 1 and input 2) the pressure drop remains constant. The results also show that the higher the injection rate, the greater the pressure drop.
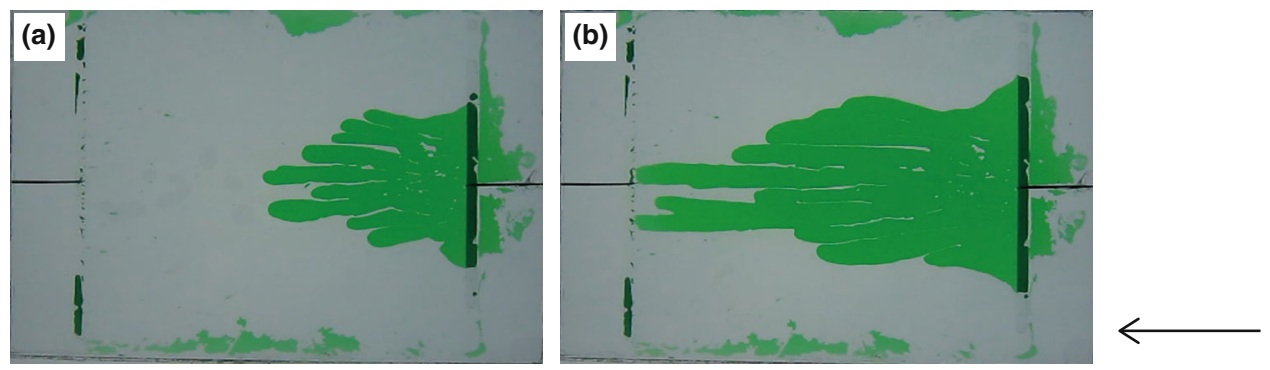

Flow in
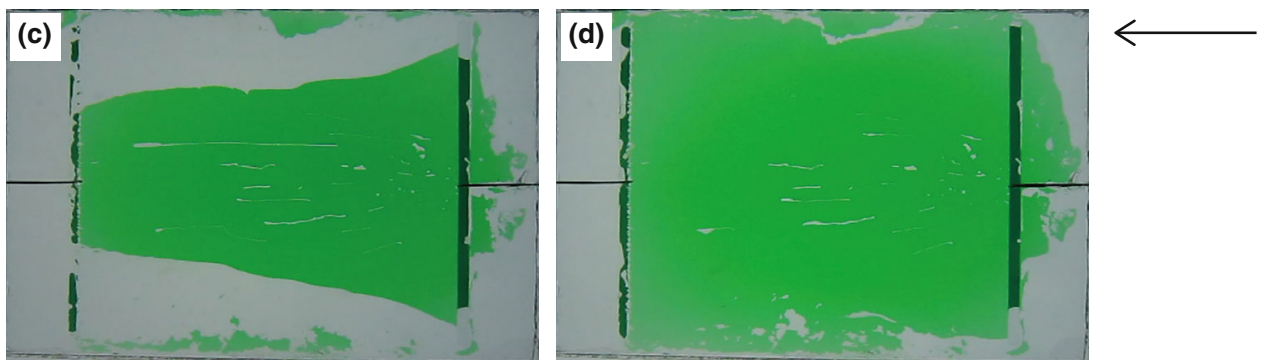

Fig. 13 Onset and propagation of fingers during waterflooding of model with distributor. a Before breakthrough. b At breakthrough. c After breakthrough. d Final state 


\subsection{The model with a distributor}

In this experiment, water was injected at the rate of $1.0 \mathrm{~mL} / \mathrm{min}$. Figure 12 shows the areal sweep efficiency versus the injection volume in the model with a distributor. In this model, several thick fingers were formed; however,

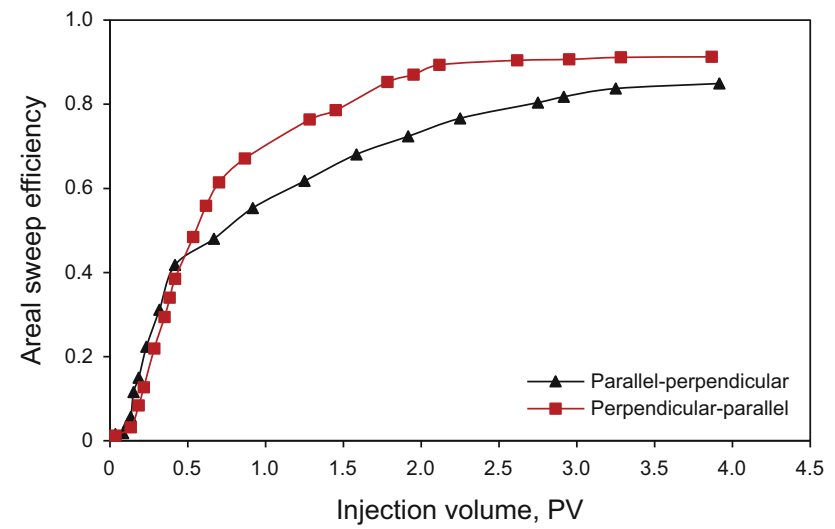

Fig. 14 Impact of heterogeneity on areal sweep efficiency before their length was increased, they joined to each other. Hence, the displacing front consisted of several thick and short fingers (Fig. 13a-d). This could be the main reason of low oil trapping (high areal sweep efficiency compared to the model without a distributor) in such a model. Another point that was observed is that after breakthrough no more fingers were formed during waterflooding.

\subsection{Heterogeneous models}

As it was mentioned earlier, two experiments were performed with a fractured model. The perpendicular fracture acted such as a distributor, which led to higher displacement efficiency. When water exited from the perpendicular fracture, several parallel short fingers formed which would improve the areal sweep efficiency. The parallel fracture acted in order to join fingers. In this circumstance, a single finger was formed and a considerable area of the model remained unswept. This led to poor sweep efficiency. More unswept region remained in the model if the perpendicular fracture was not located behind the parallel one. In the second water flooding which water first entered the parallel

Table 4 Experimental results in different scenarios performed with fractured models

\begin{tabular}{lllllll}
\hline Model & $\begin{array}{l}\text { Injection } \\
\text { direction }\end{array}$ & $\begin{array}{l}\text { Flow rate } Q, \\
\mathrm{~mL} / \mathrm{min}\end{array}$ & $\begin{array}{l}\text { Enter in perpendicular } \\
\text { fracture, s }\end{array}$ & $\begin{array}{l}\text { Enter in parallel } \\
\text { fracture, s }\end{array}$ & $\begin{array}{l}\text { Breakthrough } \\
\text { time, s }\end{array}$ & $\begin{array}{l}\text { Final areal sweep } \\
\text { efficiency }\end{array}$ \\
\hline Fractured & $\begin{array}{c}\text { Perpendicular- } \\
\text { parallel } \\
\begin{array}{c}\text { Parallel- } \\
\text { perpendicular }\end{array}\end{array}$ & 1.0 & 9 & 14 & 22 & 0.91 \\
& 1.0 & 9 & 4 & 18 & 0.85 \\
\hline
\end{tabular}
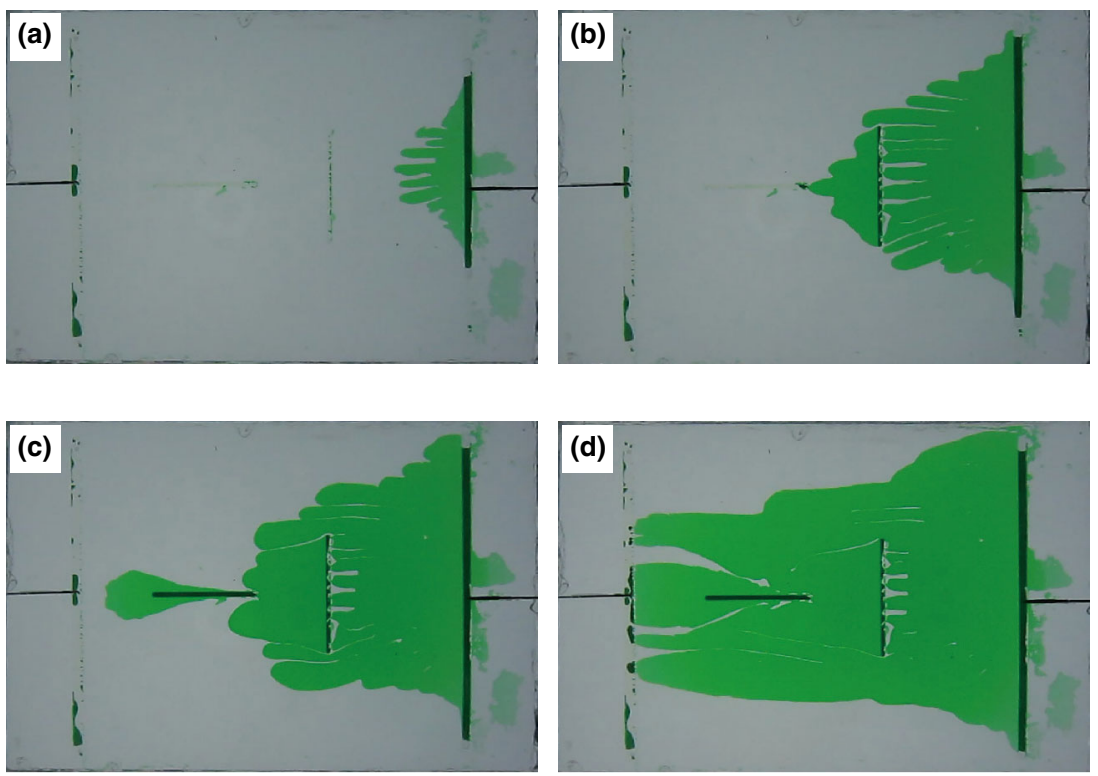

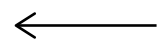

Flow in

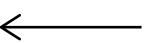

Fig. 15 Onset and propagation of fingers during heterogeneous flooding (perpendicular then parallel fractures). a Water exits from a distributor. b Water exits from the perpendicular fracture. c Water exits from the parallel fracture. d After breakthrough 

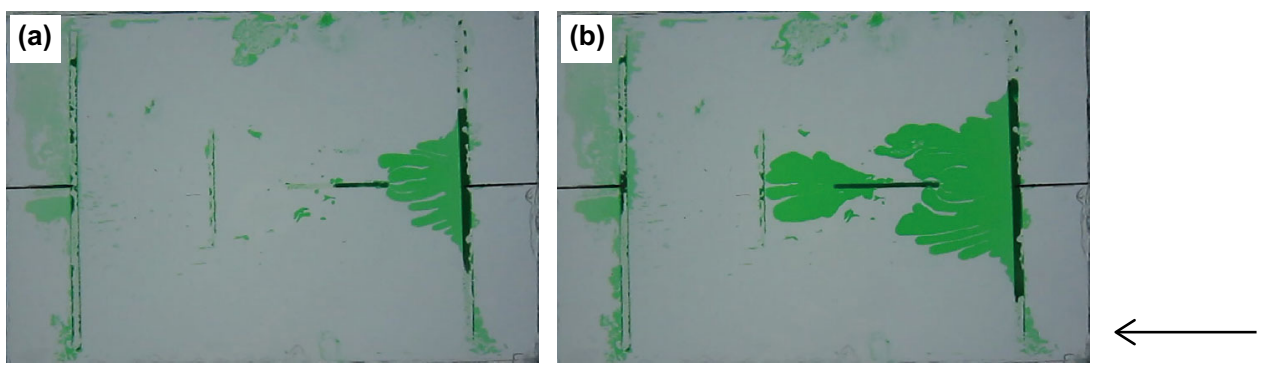

Flow in
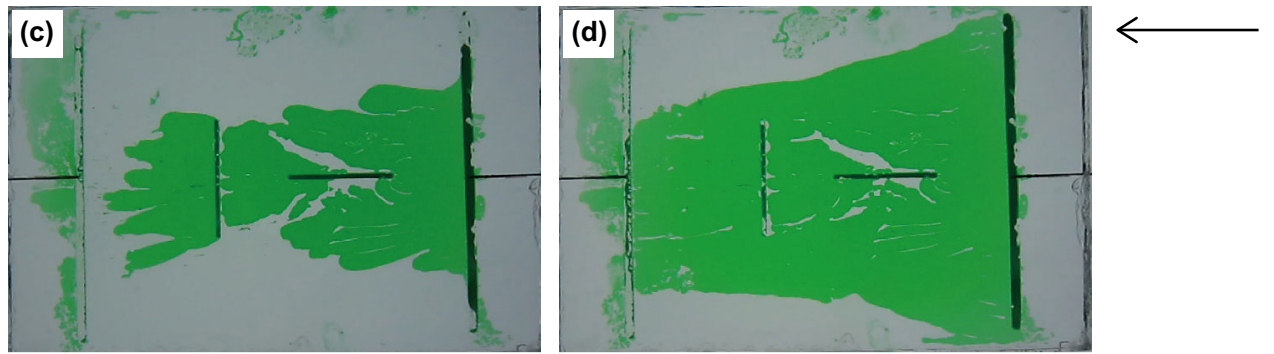

Fig. 16 Onset and propagation of fingers during heterogeneous flooding (parallel then perpendicular fractures). a Water enters the parallel fracture. b Water leaves the parallel fracture. c Water exits from the perpendicular fracture. d After breakthrough

fracture, lower sweep efficiency and earlier breakthrough were observed at the same injection volume compared with other case as can be seen from Fig. 14 and Table 4. The onset and growth of fingers in the presence of fractures are also shown in Figs. 15a-d and 16a-d.

\section{Conclusions}

Based on the experimental results of this visualization study, the following conclusions can be drawn:

1. Although viscous fingering is normally known to hinder the oil recovery efficiency, however depending on the size and the way of their growth fingers could improve the sweep efficiency as it was shown in the two-dimensional Hele-Shaw model.

2. Increasing the number of branches as well as widening of the branches compared to growing as a single narrow finger would develop higher sweep efficiency in the model.

3. A critical rate was noticed through this experimental study. Above the critical flow rate, higher injection rate adversely affects the displacement through fingering. However, it should be noted that increasing the flow rate up to the critical value is helpful because of the greater effect of viscous force to overcome the capillary force, which is known as the oil trapping force.

4. More injection wells would improve the areal sweep efficiency and decrease the negative impact of viscous fingering. Compared to one input/one output model, the existences of two inputs could give higher areal sweep efficiency with the same injection pore volume.

5. The results show that fractures perpendicular to the direction of flow could more uniformly distribute the displacing water, while fractures in the direction of flow would leave considerable area of the model upswept.

Acknowledgements The authors would like to acknowledge excellent programming assistance from Mr. Ehsan Nikooee. We also thank Shiraz University Enhanced Oil Recovery (EOR) Research Center for the support.

Open Access This article is distributed under the terms of the Creative Commons Attribution 4.0 International License (http://creative commons.org/licenses/by/4.0/), which permits unrestricted use, distribution, and reproduction in any medium, provided you give appropriate credit to the original author(s) and the source, provide a link to the Creative Commons license, and indicate if changes were made.

\section{References}

Blackwell R, Rayne J, Terry W. Factors influencing the efficiency of miscible displacement. SPE-1131-G: Society of Petroleum Engineers; 1959.

Chuoke R, Van Meurs P, van der Poel C. The instability of slow immiscible viscous liquid-liquid displacements in permeable media. SPE-1141-G: Society of Petroleum Engineers; 1959.

Collins RE. Flow of fluids through porous materials. Tulsa: Petroleum Publishing Co.; 1976.

Duan S, Wojtanowicz A. Laboratory investigation of immiscible transverse dispersion using Hele-Shaw experiment. In: Canadian international petroleum conference, 12-14 June 2007, Calgary, Alberta; 2007. https://doi.org/10.2118/2007-187. 
Fanchi JR, Christiansen R. Applicability of fractals to the description of viscous fingering. In: SPE annual technical conference and exhibition, 8-11 Oct 1989, San Antonio, Texas; 1989. https:// doi.org/10.2118/19782-MS.

Fanchi JR, Shank GD, Christiansen RL. Chaos: a source of miscible viscous fingering instabilities. In: CIM/SPE international technical meeting, 10-13 June 1990, Calgary, Alberta, Canada; 1990. https://doi.org/10.2118/21587-MS.

Greenkorn R, Haselow J. Unstable flow in heterogeneous porous media. SPE-17114-MS. Society of Petroleum Engineers; 1988.

Hamida T, Babadagli T. Effects of ultrasonic waves on immiscible and miscible displacement in porous media. In: SPE annual technical conference and exhibition; 9-12 Oct 2005, Dallas, Texas; 2005. https://doi.org/10.2118/95327-MS.

Haralick RM, Shapiro LG. Computer and robot vision. Reading: Addison-Wesley; 1992.

Kim H, Funada T, Joseph DD, Homsy G. Viscous potential flow analysis of radial fingering in a Hele-Shaw cell. Phys Fluids. 2009;21(7):074106. https://doi.org/10.1063/1.3184574.

Lake LW. Enhanced oil recovery. Englewood Cliffs: Prentice Hall; 1989.

Løvoll G, Méheust Y, Måløy KJ, Aker E, Schmittbuhl J. Competition of gravity, capillary and viscous forces during drainage in a twodimensional porous medium, a pore scale study. Energy. 2005;30(6):861-72. https://doi.org/10.1016/j.energy.2004.03. 100.

Martin J, Rakotomalala N, Salin D. Gravitational instability of miscible fluids in a Hele-Shaw cell. Phys Fluids. 2002;14(2):902-5. https://doi.org/10.1063/1.1431245.

Perkins TK, Johnston OC, Hoffman RN. Mechanics of viscous fingering in miscible systems. SPE J. 1965;5(04):301-17. https:// doi.org/10.2118/1229-PA.
Peters EJ, Flock DL. The onset of instability during two-phase immiscible displacement in porous media. SPE J. 1981;21(02):249-58. https://doi.org/10.2118/8371-PA.

Saffman P. Viscous fingering in Hele-Shaw cells. J Fluid Mech. 1986;173:73-94. https://doi.org/10.1017/S0022112086001088.

Saffman PG, Taylor G. The penetration of a fluid into a porous medium or Hele-Shaw cell containing a more viscous liquid. Proc R Soc Lond A. 1958;245(1242):312-29. https://doi.org/10. 1098/rspa.1958.0085.

Sarma H. Viscous fingering: one of the main factors behind poor flood efficiencies in petroleum reservoirs. Powder Technol. 1986;48(1):39-49. https://doi.org/10.1016/00325910(86)80063-8.

Turta A, Ayasse C, Najman J, Fisher D, Singhal A. Laboratory investigation of gravity-stable waterflooding using toe-to-heel displacement: Part L: Hele Shaw model results. In: SPE international thermal operations and heavy oil symposium and international horizontal well technology conference; 2002. https://doi.org/10.2118/78988-MS.

Voroniak A, Bryan J, Taheri S, Hejazi H, Kantzas A. Investigation of post-breakthrough heavy oil recovery by water and chemical additives using Hele-Shaw cell. In: SPE Latin America and Caribbean heavy and extra heavy oil conference; 2016. https:// doi.org/10.2118/181149-MS.

Weitz D, Stokes J, Ball R, Kushnick A. Dynamic capillary pressure in porous media: origin of the viscous-fingering length scale. Phys Rev Lett. 1987;59(26):2967. https://doi.org/10.1007/s11242010-9622-8.

Zimmerman W, Homsy G. Nonlinear viscous fingering in miscible displacement with anisotropic dispersion. Phys Fluids A Fluid Dyn. 1991;3(8):1859-72. https://doi.org/10.1063/1.857916. 